\title{
How do ACE inhibitors reduce mortality in patients with left ventricular dysfunction with and without heart failure: remodelling, resetting, or sudden death?
}

\author{
John G F Cleland, Sundeep Puri
}

The benefits of ACE inhibitors as standard treatment for patients with overt heart failure due to ventricular dilatation and systolic dysfunction are proved beyond reasonable doubt, at least when a diuretic has been used to control symptoms. More recent studies have suggested that ACE inhibitors may delay or prevent the onset of heart failure requiring diuretics in patients with obviously impaired ventricular function. ${ }^{12}$ However, although the benefits of ACE inhibitors in clinical practice are well established, the mechanisms underlying the beneficial effect at the cellular, organ, and clinical level are poorly characterised. Other articles in this supplement have dealt with the more basic mechanisms underlying ACE inhibitor action. In this article we reevaluate the clinical nature of left ventricular remodelling and consider to what extent it accounts for the beneficial effects of ACE inhibitors on outcome in patients with established ventricular dysfunction with or without heart failure.

\section{Left ventricular remodelling, cardioprotection, and cardioreparation Although the introduction of neologisms without good reason is generally to be deplored, some new terms have been coined that have helped our understanding of how the heart responds to ventricular damage and to beneficial interventions. These terms and proposed definitions are shown in table 1 . \\ Progressive ventricular remodelling is com- plex, entailing changes at many levels, and is associated with a poor prognosis. ${ }^{3} 4 \mathrm{Re}-$ modelling after myocardial infarction has been intensively studied as the process occurs rapidly in response to dramatic changes in ventricular function ${ }^{5}{ }^{6}$; remodelling in hypertension and chronic heart failure is slower. $^{78}$ At the cellular level changes in the function, morphology, and distribution of the cardiac myocyte ${ }^{9}$ occur, as well as changes in the type, structure, and amount of collagen ${ }^{10}$;}

Table 1 Some suggested definitions

Definition

\begin{tabular}{ll} 
Table 1 Some suggested definitions \\
\hline Definition \\
\hline Cardioprotection & $\begin{array}{c}\text { Alteration in the contour or volume of left ventricular cavity } \\
\text { that is not attributable to short term changes in distending } \\
\text { pressure } \\
\text { Prevention or retardation of pathological remodelling by } \\
\text { suitable treatment } \\
\text { Restoration of the diseased heart towards its normal structure } \\
\text { and function }\end{array}$ \\
\hline
\end{tabular}

an inflammatory cell infiltrate is common. ${ }^{11}$ In the myocardium both contractility and relaxation are impaired and hypertrophy occurs. ${ }^{12}$ In the ventricle volume is increased, ${ }^{13}$ the shape becomes more globular, ${ }^{14}$ and hypertrophy occurs, though the latter is rarely enough to normalise wall stress. ${ }^{15}$ Ventricular compliance increases, ${ }^{8}$ possibly reflecting changes in collagen structure or the increased wall stress associated with ventricular dilatation.

Remodelling after infarction may affect the scar, the peri-infarction zone, and noninfarcted regions of the heart. Attempts to interfere with the process of remodelling itself may be deleterious. Thus indomethacin and steroids reduce the inflammatory infiltrate in infarcted areas of myocardium, but they result in further thinning and expansion of the scar and ventricular dilatation. ${ }^{11} 16$ Indeed, ventricular remodelling may be a useful adaptation to haemodynamic stress; ventricular dilatation allows stroke volume to be maintained with less myocardial fibre shortening, and increased ventricular compliance will delay increases in filling pressures. ${ }^{17}$ Failure of appropriate remodelling to haemodynamic stress may account for the worse prognosis of older patients with heart failure or myocardial infarction, or both, in whom gross ventricular dilatation is rare.

\section{How common is remodelling?}

Theoretically, many aspects of remodelling should be a continuous response to the changing demands on the ventricle in health and disease. However, progressive ventricular remodelling does not seem to occur after all myocardial infarctions or in all cases of heart failure. In many cases ventricular volumes remain stable for years. ${ }^{34}$ This will reflect technical difficulties with the reproducibility of measurements in some patients and a lack of or a reduction in ventricular haemodynamic stress in others. After myocardial infarction an acute period of dilatation may be followed by a reduction in volumes towards baseline due either to the functional recovery of stunned myocardium or to the contraction of myocardial scars. ${ }^{15}$ Myocardial fibrosis probably contributes to the lack of obvious ventricular dilatation in many elderly patients with heart failure.

Remodelling is more likely to occur with larger infarcts, especially in the anterior 
territory. ${ }^{18}$ Thrombolytic treatment attenuates left ventricular dilatation after infarction, ${ }^{19}$ probably by reducing infarct size, but reperfusion may also be important in itself. ${ }^{20}$ Additional angioplasty does not seem to confer greater benefit. ${ }^{21}$ Whereas establishing early patency of the infarct related artery may reduce the size of the myocardial infarction and seems to be associated with improved survival, ${ }^{22}{ }^{23}$ the importance of late infarct related artery patency in preventing remodelling is unclear. A poor collateral supply ${ }^{24}$ and persistent occlusion of the infarct related artery $^{25}$ are associated with a poorer prognosis. However, late patency may not be intrinsically important to the dilating process as completed transmural infarcts require little coronary blood flow and the lack of requirement for a blood supply may lead to the disappearance of the vessel. Thus, the relation between remodelling and late infarct related artery patency may be one of association rather than cause and effect.

Diabetic patients have a worse prognosis after myocardial infarction, which seems to be because of a greater propensity to develop heart failure for any given size of infarct; but it is not known if this is due to a different propensity for remodelling. ${ }^{26}$ Hypertensive patients also have a worse prognosis after myocardial infarction, but this seems mainly because of a greater risk of reinfarction..$^{27}$ The hypertrophied ventricle may be less likely to develop infarct expansion. ${ }^{28}$

\section{Relation of remodelling to prognosis} Left ventricular dilatation developing after a myocardial infarction is associated with a poorer prognosis. ${ }^{12} 13$ Similarly, ventricular volume is a major determinant of prognosis in patients with dilated cardiomyopathy. ${ }^{29}$ Not only is a low ejection fraction a bad prognostic sign but a decline in ejection fraction with time indicates a worse outcome. ${ }^{4}$ Ventricular dilatation leads to an increase in wall stress and progressive distension, and this may be a major determinant of outcome. Remodelling may, however, be a marker rather than a cause of worse outcome. The forces leading to remodelling may be the major determinant of prognosis rather than the ventricular dilatation itself. Obvious dilatation is often associated with severe symptoms, high filling pressures, and low cardiac output. However, patients with obvious ventricular dilatation and a good exercise tolerance may have a better prognosis than those with minimally dilated ventricles and severe symptoms associated with appreciable haemodynamic compromise. ${ }^{30}$

\section{Effects of interventions on ventricular remodelling}

Several treatments can alter ventricular remodelling, not all of them beneficially as described above, but ACE inhibitors are the only class of agent that has been well studied.

After myocardial infarction there is limited evidence for a favourable effect of nitrates on remodelling, ${ }^{31}$ which has not been supported by clinical evidence of benefit in recent large trials. $^{32}{ }^{33}$ Loop diuretics ${ }^{6}$ and digoxin ${ }^{34}$ do not seem to alter remodelling favourably, while captopril, ${ }^{33}$ probably magnesium, ${ }^{35}$ and calcium antagonists ${ }^{3637}$ do not reduce the risk of developing heart failure after myocardial infarction. $\beta$ Blockers reduce the risk of developing heart failure in selected patients after myocardial infarction ${ }^{38}$ and can improve haemodynamics and increase ejection fraction in patients with dilated cardiomyopathy. ${ }^{39}$

Non-pharmacological interventions may also alter the remodelling process. In patients with dilated, poorly functioning ventricles and severe coronary stenoses subtending a large amount of viable myocardium, revascularisation may result in appreciable improvements in volume and function. ${ }^{40}$ Limited data also suggest that other techniques such as haemofiltration ${ }^{41}$ or the correction of sleep apnoea ${ }^{41}$ can improve ventricular function, apparently independent of haemodynamic effects.

\section{Effects of ACE inhibitors on ventricular} volume and ejection fraction

The effects of ACE inhibitors on the remodelling process after myocardial infarction are dealt with in this supplement. ${ }^{42}{ }^{43}$ Briefly, ACE inhibitors reduce cardiac volumes, and the major impact seems to be through reducing the extent to which anterior scars expand, ${ }^{44}$ with lesser effects on dilatation of the non-infarct zone. Thrombolysis may reduce both the frequency of progressive remodelling ${ }^{19} 45$ and the impact of ACE inhibitors on left ventricular dilatation, ${ }^{46}$ while persistent occlusion of the infarct related artery may reflect a greater tendency to dilate and a greater benefit from ACE inhibition. ${ }^{47}$

ACE inhibitors reduce both systolic and diastolic ventricular volumes in patients with heart failure, and this effect occurs within six weeks of starting treatment. ${ }^{48}{ }^{49}$ These short term changes are readily reversible ${ }^{48} 49$ and associated with improved haemodynamics; they are therefore not good evidence for remodelling as defined above.

The SOLVD studies used echocardiography and radionuclide ventriculography to show that enalapril reduced ventricular volumes over 3-4 years. ${ }^{7} 850$ The radionuclide substudy of SOLVD showed, however, that the largest change in volume occurred in the first four months; thereafter there was no apparent difference in the rate of ventricular dilatation. This comparatively short term effect might be termed "resetting" rather than remodelling, ${ }^{51}$ the latter implying a process of continuing improvement. The change in ventricular volumes did not seem to be solely due to an effect of enalapril on haemodynamics because, although ventricular volumes rose after withdrawal of enalapril for two weeks at the end of the study, they were still reduced compared with placebo.

The captopril-digoxin multicentre ${ }^{52}$ and V-HeFT II studies, ${ }^{53}$ the largest radionuclide 
ventriculographic studies of ACE inhibitors in heart failure, failed to show a significant long term effect of ACE inhibitors on ejection fraction. By contrast, the combination of hydralazine and nitrates led to an increase in ejection fraction in the V-HeFT II study. These studies did not provide information on cardiac volumes, and therefore a balanced reduction in systolic and diastolic volumes by ACE inhibitors cannot be excluded.

\section{Effects of ACE inhibitors on ventricular hypertrophy}

Hypertrophy in response to an increase in ventricular wall stress or neuroendocrine mediators, or both, is a characteristic feature not only of hypertension but also of heart failure. ${ }^{54}$ As ventricular dilatation is usual in heart failure, hypertrophy is usually eccentric and is therefore less obvious on imaging. ACE inhibitors are effective in reducing hypertrophy in hypertension, ${ }^{55}$ but what happens in heart failure is less clear. Rather than a regression of hypertrophy the SOLVD study indicated that enalapril prevented ventricular mass from increasing. ${ }^{50}$ Therefore, cardiac volumes fall either before or to a greater extent than the decline in ventricular hypertrophy. This may be because haemodynamic stress rather than neuroendocrine activation is the dominant factor in determining ventricular hypertrophy in heart failure. The preferential and earlier reduction in volume means that the ratio of mass to volume increases with concomitant reductions in wall stress that should have beneficial effects on ventricular function and possibly survival.

\section{Effects of ACE inhibitors on ventricular compliance}

Although myocardial compliance is decreased in heart failure, ventricular compliance is paradoxically increased, reflecting the increase in wall stress secondary to dilatation. Data from the SOLVD study suggest that long term ACE inhibition reduces filling pressures to a lesser extent than ventricular diastolic volume: thus for a given ventricular volume, filling pressure tends to rise. ${ }^{54}$ This implies that ACE inhibitors reduce ventricular compliance towards normal.

Doppler studies in patients with chronic ventricular dysfunction do not indicate an important effect of ACE inhibitors on ventricular filling patterns, ${ }^{55}$ although studies in patients with heart failure have suggested an improvement in the early rapid filling phase. ${ }^{56} \mathrm{ACE}$ inhibitors used in the short term after myocardial infarction also seem to improve Doppler filling characteristics long term. ${ }^{57}$ Improvements in ventricular filling under some circumstances may be due to direct effects on the myocardium but could also be due to changes in ventricular loading conditions.

\section{Effects of ACE inhibitors on peripheral vascular structure}

Studies in hypertension have highlighted the structural changes that occur in arterioles.
Experimental evidence from animal studies suggests that the histological changes induced by hypertension may be reversed by ACE inhibitors, ${ }^{58}$ though this awaits confirmation in humans.

In heart failure maximal vasodilatation induced by drugs or metabolic stress is reduced, suggesting that structural changes in the systemic vasculature may be important in regulating blood flow. ${ }^{59}$ Alveolar-capillary membrane dysfunction leading to a decline in pulmonary diffusing capacity in heart failure may represent similar structural changes in the pulmonary vasculature. ${ }^{60}$ Although ACE inhibitors reduce vascular resistance both at rest and during exercise, it is unclear how much of this is due to a beneficial effect on vascular remodelling.

\section{Effects of ACE inhibitors on recurrent infarction}

Recurrent infarction causes progressive ventricular damage and confers a greater risk of developing heart failure or dying. The arguments for and against a significant impact of ACE inhibitors on reinfarction have been discussed previously. ${ }^{43}$ The results of QUIET (quinapril ischaemic event trial), investigating the effects of quinapril on recurrent ischaemic events in patients with coronary disease but no substantial ventricular dysfunction, will be critical in resolving these arguments.

\section{Effects of ACE inhibitors on salt and water balance}

ACE inhibitors are believed to reduce sodium and water retention, though this assumption is based mostly on experiments in animals or in normal and hypertensive human subjects.

By contrast, patients with heart failure commonly retain salt and water in the first few days after taking an ACE inhibitor. ${ }^{61}$ This suggests that the fall in renal perfusion pressure, glomerular filtration rate, and atrial natriuretic peptide concentration in response to ACE inhibition prevents any potentially natriuretic effect due to a decline in angiotensin II and aldosterone concentrations. However, salt and water retention is generally self limiting and not accompanied by clinical deterioration, presumably because central haemodynamics improve. Over 6-8 weeks sodium retention is reversed and returns to pretreatment values. ${ }^{48} 49$ Thirty four studies have compared the effects of ACE inhibitors and placebo on symptoms in patients with heart failure, but weight was recorded in only 11. Only two studies showed a reduction in weight, suggesting that most of the patients studied did not show diuresis.

\section{Effects of ACE inhibitors on}

arrhythmias

Whether ACE inhibitors exert a beneficial effect on arrhythmias remains controversial. Several small studies ${ }^{484962}$ and the V-HeFT $I^{63}$ and SAVE studies ${ }^{64}$ suggest that 
ACE inhibitors reduce arrhythmias, but the SOLVD study did not. ${ }^{65}$ ACE inhibitors improve ventricular loading conditions, reduce volumes and retard progressive hypertrophy, increase serum potassium concentrations and parasympathetic tone, and reduce sympathetic activity, so it would not be surprising if they reduced arrhythmias. ${ }^{66}$ The reason why the smaller early crossover studies were successful in showing a modest decrease in the frequency of ventricular extrasystoles may reflect the fact that hypokalaemia was common at baseline. The reduced intraindividual variability in ectopic beats in patients with a high frequency of arrhythmias probably also contributed to the ability of these studies to show an effect of ACE inhibitors.

Animal studies have subsequently confirmed that ACE inhibitors have antiarrhythmic effects. These models suggest that modulation of the cardiac sympathetic system or the bradykinin-prostaglandin system may be important in mediating the electrophysiological effects of ACE inhibitors ${ }^{67}$ Studies of ACE inhibitors in human heart failure have suggested only subtle electrophysiological effects, but these may, none the less, be important. ${ }^{68}$

\section{Effects of ACE inhibitors on sudden death}

Results from both small and large trials have suggested that ACE inhibitors may affect sudden death as well as death due to progressive heart failure. ${ }^{15369-71}$ Sudden death should no longer be equated with death from arrhythmias in heart failure. The frequency of documented recurrent myocardial infarction in patients with heart failure and the adverse effect on prognosis suggests that many such sudden deaths are vascular rather than arrhythmic in origin. ${ }^{72}$ Postmortem studies indicate that in $74 \%$ of patients with ischaemic heart disease who die suddenly death is associated with fresh thrombus in the coronary artery. ${ }^{73}$ As ACE inhibitors may reduce the risk of recurrent infarction a reduction in the number of sudden deaths might also occur by this mechanism. ${ }^{43}$

The first study to report on the influence of ACE inhibitors on the mode of death was the captopril multicentre trial, which indicated a striking reduction in the number of sudden deaths, though numbers were small. ${ }^{69}$ Several large studies of heart failure, with the exceptions of the CONSENSUS ${ }^{74}$ and the SOLVD treatment trial, ${ }^{75}$ have recorded sudden death, either with or without progression, as the most common mode of death.

In the CONSENSUS study the patients had severe heart failure. The more severe the heart failure the greater the likelihood that death will be classified as progressive heart failure. ${ }^{76}$ This may indicate that the real mode of death is influenced by the severity of heart failure, which is entirely plausible. Alternatively, if patients already confined to bed by symptoms die suddenly it is likely that the death will be recorded as progressive heart failure rather than sudden death. In the SOLVD treatment trial the investigators chose to report death due to progressive heart failure and sudden death in the context of worsening heart failure as one and the same. This may be why sudden death accounted for only about $20 \%$ of deaths in that study. Distinguishing sudden death in the context of worsening heart failure from death due to worsening heart failure alone is important not only because it would provide a more accurate view of the clinical course of heart failure but also because sudden death may be amenable to other treatment strategies, which may be important in, for instance, patients awaiting cardiac transplantation. However, the SOLVD studies suggested a reduction in both sudden death and myocardial infarction ${ }^{72}$-an effect that was not significantly different from the effect on the combined sudden death/progressive heart failure group. Interestingly, enalapril reduced mortality even during the run in period. ${ }^{75}$ As it would be surprising if patients with rapidly deteriorating heart failure were considered for a randomised study, one possible explanation for the positive effect of enalapril during this phase was a reduction in sudden death.

In the V-HeFT II study the effect of enalapril was entirely due to a reduction in sudden death with or without a concomitant deterioration in symptoms. ${ }^{53}$ It is possible that the combination of hydralazine and nitrate may increase the risk of sudden death and that the use of an active comparator rather than placebo led to the apparent beneficial effect on sudden death, but this is unlikely as the vasodilator combination probably has a beneficial effect on survival. ${ }^{77}$ Alternatively, the conventional vasodilator combination could have selectively reduced death from progressive heart failure alone, while enalapril reduced death by either mechanism; this cannot be discounted. The SAVE study also showed a reduction in mortality due to progression of heart failure alone and sudden death with or without progressive heart failure. ${ }^{1}$

In summary, the landmark studies have failed, so far, to convincingly identify the mechanism by which ACE inhibitors reduce mortality from heart failure. Undoubtedly, ACE inhibitors reduce ventricular volumes, but it is unclear whether the principal reason for this is an acute resetting of volumes mediated primarily through reduced haemodynamic stress; retardation of progressive remodelling through alterations in ventricular stress and inhibition of neuroendocrine activation; or prevention of recurrent ischaemic damage to the left ventricle (table 2).

Table 2 Mechanisms by which ACE inhibitors might reduce progressive ventricular dilatation

Mechanism

Reduction in ventricular preload and afterload
Resetting of ventricular volumes (possibly secondary to the Resetting above)

Remodelling (secondary to haemodynamic and

effects)

Reduction in recurrent ischaemia and infarction 
1 Pfeffer M, Braunwald E, Moye LA, et al. Effect of captopril on mortality and morbidity in patients with left ventricular dysfunction after myocardial infarction. $N$ Engl f Med 1992;327:669-77.

2 SOLVD Investigators. Effect of enalapril on mortality and the development of heart failure in asymptomatic patients with reduced left ventricular ejection fractions. $N$ Engl F Med 1992;327:685-91

3 White HD, Norris RM, Brown MA, et al. Left ventricular end-systolic volume as the major determinant of survival after recovery from myocardial infarction. Circulation 1987;76:44-51.

4 Cintron G, Johnson G, Francis G, Cobb F, Cohn JN, for the V-HeFT VA Cooperative Studies Group. Prognostic significance of serial changes in left ventricular ejection fraction in patients with congestive heart failure. fraction in patients with congestive
Circulation 1993;87(suppl 6):VI-17-23.

5 Sharpe N, Murphy J, Smith H, Hannan S. Treatment of patients with symptomless left ventricular dysfunction patients with symptomless left ventricular dysfun
after myocardial infarction. Lancet 1988;i:255-9.

6 Sharpe N, Smith H, Murphy J, Greaves S, Hart H, Gamble G. Early prevention of left ventricular dysfunction following myocardial infarction. Lancet 1991;i:872-4.

7 Konstam MA, Rousseau MF, Kronenberg MW, et al. Effects of the angiotensin converting enzyme inhibitor enalapril on the long-term progression of left ventricular dysfunction in patients with heart failure. Circulation 1992;86:431-8.

8 Konstam MA, Kronenberg MW, Rousseau MF, et al, for the SOLVD Investigators. Effects of the angiotensin converting enzyme inhibitor enalapril on the long-term progression of left ventricular dilatation in patients with asymptomatic systolic dysfunction. Circulation 1993; 88:2277-83.

9 Weisman HF, Bush DE, Mannisi JA, Weisfeldt ML, Healy B. Cellular mechanisms of myocardial infarct expansion. Circulation 1988;78:186-201.

10 Weber KT, Brilla CG, Janicki JS. Myocardial fibrosis: functional significance and regulatory factors. Cardiovasc Res 1993;27:341-8.

11 Mannisi JA, Weisman HF, Bush DE, Dudeck P, Healy B. Steroid administration after myocardial infarction
promotes early infarct expansion: a study in the rat. $\mathcal{F}$ promotes early infarct expansi

12 Anversa P, Beghi C, Kikkawa Y, Olivetti G. Myocardial infarction in rats: infarct size, myocyte hypertrophy and capillary growth. Circ Res 1986;58:26-67.

13 Hammermeister KE, DeRouen TA, Dodge HT. Variables predictive of survival in patients with coronary disease: selection by univariate and multivariate analyses from the clinical, electrocardiographic exercise, arteriographic and quantitative angiographic evaluations. Circulation 1979; 59:421-30.

14 Lamas GA, Vaughan DE, Parisi Af, Pfeffer MA. The effects of left ventricular shape and captopril therapy on exercise capacity after anterior wall acute myocardial infarction. Am f Cardiol 1989;63:1167-73.

15 Rumberger JA, Behrenbeck T, Breen JR, Reed JE, Gersh BJ. Nonparallel changes in global left ventricular chamber volume and muscle mass during the first year after transmural myocardial infarction in humans. $7 \mathrm{Am}$ Coll Cardiol 1993;21:673-82.

16 Hammerman H, Schoen FJ, Braunwald E, Kloner RA. Drug-induced expansion of infarct: morphologic and functional correlations. Circulation 1984;69:611-7.

17 Gaudron P, Eilles C, Kugler I, Ertl G. Progressive left ventricular dysfunction and remodelling after myocardial ventricular dysfunction and remodelling
infarction. Circulation 1993;87:755-63.

18 Oldroyd KG, Pye MP, Ray SG, et al. Effects of early captopril administration on infarct expansion, left ventricular remodelling and exercise capacity after acute myocardial infarction. Am $\mathcal{F}$ Cardiol 1991;68:713-8.

19 ISAM Study Group. A prospective trial of intravenous streptokinase in acute myocardial infarction (ISAM): mortality, morbidity and infarct size at 21 days. $N$ Engl $\mathcal{F}$ Med 1986;314:1465-71

20 Jeremy RW, Hackworth RA, Bautowich G, Hutton BF, Harris PJ. Infarct artery perfusion and changes in left ventricular volume in the month after acute myocardial infarction. $\mathcal{7}$ Am Coll Cardiol 1987;9:989-95.

21 Nixdorff U, Mohr-Kahaly S, Wittlich N, Schiketanz KH. Left ventricular remodelling is not prevented by PTCA of the infarct related artery [abstract]. Circulation 1993; 88(suppl):I-160.

22 ISIS-2 (second international study of infarct survival) Collaborative Group. Randomised trial of intravenous streptokinase, oral, aspirin, both, or neither among 17 187 cases of suspected acute myocardial infarction: ISIS-2. Lancet 1988;ii:349-60.

23 GUSTO Investigators. An international randomised trial comparing four thrombolytic strategies for acute comparing four thrombolytic strategies for acute
myocardial infarction. $N$ Engl $₹$ Med 1993;329:673-82.

24 Hirai T, Fujita $M$, Nakajima $H$, et al. Importance of collateral circulation for prevention of left ventricular collateral circulation for prevention of left intricular aneurysm formation in
Circulation 1989;79:791.

25 Cigarroa RG, Lange RA, Hillis LD. Prognosis after acute myocardial infarction in patients with and without residual anterograde coronary blood flow. Am f Cardiol 1989;64:155.

26 Gwilt DJ, Petri M, Lewis PW, Nattrass M, Pentecost BL. Myocardial infarct size and mortality in diabetic patients. Br Heart $\mathcal{F}$ 1985;54:466-72.

27 Herlitz J, Karlson BW, Richter A, Wilkund O, Jablonskiene
D, Hjalmarson A. Prognosis in hypertensives with acute myocardial infarction. F Hypertens 1992;13:1611-8.

28 Pirolo JS, Hutchins GM, Moore GW. Infarct expansion: pathologic analysis of 204 patients with a single myocardial infarct. $\mathcal{F}$ Am Coll Cardiol 1986;7:349-54.

29 Komajda M, Jais JP, Reeves F, et al. Factors predicting mortality in idiopathic dilated cardiomyopathy. Eur Heart f 1990;11:824-31.

30 Keren A, Gottlieb S, Tzivoni D, et al. Mildly dilated congestive cardiomyopathy. Circulation 1990;81:506-17.

31 Jugdutt BI, Warnica JW. Intravenous nitroglycerine therapy to limit myocardial infarct size, expansion and complications. Effect of timing, dose and infarct location. Circulation 1988;78:906-19.

32 Gruppo Italiano per lo Studio della Sopravvivenza nell'Infarto Miocardico. GISSI-3: effects of lisinopril and transdermal glyceryl trinitrate singly and together on 6-week mortality and ventricular function after acute 6-week mortality and ventricular function after
myocardial infarction. Lancet 1994;343:1115-22.

33 ISIS Collaborative Group. ISIS-4. Randomised study of oral captopril in over 50000 patients with suspected acute myocardial infarction. Circulation 1993;88(suppl): acute

34 Bonaduce D, Petretta M, Arrichiello P, et al. Effects of captopril treatment on left ventricular remodelling and function after antion: comparison with digitalis. $\mathcal{f}$ Am Coll Cardiol 1992;19:858-63.

35 woods KL, Fletcher S, Roffe C, Haider Y. Intravenous magnesium sulphate in suspected acute myocardial infarction: results of the second Leicester intravenous magnesium intervention trial (LIMIT-2). Lancet 1992; 339:1553-8

36 Goldstein RE, Boccuzzi SJ, Cruess D, et al; the Adverse Experience Committee; and the Multicenter Diltiazem Postinfarction Research Group. Diltiazem increases lateonset congestive heart failure in postinfarction patients with early reduction in ejection fraction. Circulation 1991;83:52-60.

37 Goldbourt U, Behar S, Reicher-Reiss H, Zion M, Mandelzweig L, Kaplinsky E, for the SPRINT Study Group. Early administration of nifedipine in suspected Group. Early administration of nifedipine in suspected acute myocardial infarction. The secondary prevention
reinfarction Israel nifedipine trial 2 study. Arch Interm Med 1993;153:345-53

38 Held P. Effects of $\beta$ blockers on ventricular dysfunction after myocardial infarction: tolerability and survival after myocardial infarction: tolerability

39 Waagstein F, Bristow MR, Swedberg K, et al, for the Metoprolol in Dilated Cardiomyopathy (MDC) Trial Study Group. Beneficial effects of metoprolol in idiopathic dilated cardiomyopathy. Lancet 1993;342: 1441-6.

40 Elefteriades JA, Tolis G, Levi E, Mills LK, Zaret BL. Coronary artery bypass grafting in severe left ventricular dysfunction: excellent survival with improved ejection fraction and functional state. $\mathcal{f} \mathrm{Am}$ Coll Cardiol 1993;22:1411-7.

41 Cleland JGF. Ancillary therapy for heart failure. Current Opinion in Cardiology 1991;6:373-8.

42 Smits JFM, Daemen MJAP. Insights from animal models of myocardial infarction: do ACE inhibitors limit the structural response? Br Heart $\mathcal{F}$ 1994;72(3)(suppl):S61-4.

43 Ball SG, Hall AS. What to expect from ACE inhibitors after myocardial infarction. $B r$ Heart $\mathcal{f}$ 1994;72(3) (suppl):S70-4.

44 Ray SG, Pye M, Oldroyd KG, et al. Captopril after acute myocardial infarction. Br Heart f 1993;69:215-22.

45 white HD, Norriss RM, Brown MA, et al. Effect of intravenous streptokinase on left ventricular function and early survival after acute myocardial infarction. $N$ Engl ff Med 1987;317:850.

46 Hargreaves AD, Kolettis T, Jacob AJ, et al. Early vasodilator treatment in myocardial infarction: appropriate for the majority or minority? $\mathrm{Br}$ Heart $\mathcal{f}$ 1992;68:369-73.

47 Pfeffer MA, Lamas GA, Vaughan DE, et al. Effect of captopril on progressive ventricular dilatation after anterior myocardial infarction. $N$ Engl f Med 1988; 319:80-6.

48 Cleland JGF, Dargie HJ, Ball SG, et al. Effects of enalapril in heart failure: a double blind study of effects on exercise performance, renal functional, hormones, and metabolic state. Br Heart $\mathcal{F}$ 1985;54:305-12.

49 Cleland JGF, Dargie HJ, Hodsman GP, et al. Captopril in heart failure: a double blind controlled trial. Br Heart $\mathcal{f}$ 1984;52:530-5.

50 Greenberg $B$, Quinones $M$, Koilpillai $C$, Limacher $M$, Schindler $\mathrm{D}$, Shelton $\mathrm{B}$, for the SOLVD Investigators. Effects of long-term enalapril therapy on echocardiographic variables in SOLVD patients [abstract]. Circulation 1992;86(suppl):I-251.

51 Cleland JGF. ACE inhibitors for the prevention and treatment of heart failure: insights form the SOLVD trials. Eur Heart $\mathcal{f}$ (in press).

52 Captopril Digoxin Multi-Center Research Group. Comparative effects of therapy with captopril and digoxin in patients with mild to moderate heart failure. $7 A M A$ 1988;259:539-44.

53 Cohn JN, Johnson G, Ziesche S, et al. A comparison of enalapril with hydralazine-isosorbide dinitrate in the treatment of chronic congestive heart failure. $N$ Engl $\mathcal{F}$ Med 1991;325:303-10.

54 Pouleur HG, Konstam MA, Udelson JE, Rousseau MF Changes in ventricular volume, wall thickness and wall 
stress during progression of left ventricular dysfunction Am 7 Cardiol 1993;22(suppl):43-8A.

55 Cleland JGF, Shah D, Krikler S, et al. The effects of lisinopril on cardiorespiratory, neuroendocrine, and renal function in patients with asymptomatic left ventricular dysfunction. Br Heart f 1993;69:512-5.

56 Keren G, Pardes A, Eschar Y, Hansch E, Scherez J, Laniado S. Left ventricular filling dynamics by Doppler echocardiography in dilated cardiomyopathy: one-year follow-up in patients treated with captopril compared to placebo. Cardiology 1992;81:196-206.

57 Gotzsche CO, Sogaard P, Ravkilde J, Thygesen K. Effects of captopril on left ventricular systolic and diastolic function after acute myocardial infarction. Am $f$ Cardiol 1992;70:156-60.

58 Lee RM, Berecek KH, Tsoporis J, McKenzie R, Triggle CR. Prevention of hypertension and vascular changes by captopril treatment. Hypertension 1991;147:141-50.

59 Zelis R. Mason DT, Braunwald E. A comparison of the effects of vasodilator stimuli on peripheral resistance vessels in normal subjects and in patients with congestive heart failure. 7 Clin Invest 1968;47:960-70.

60 Puri S, Baker BL, Oakley CM, Hughes JMB, Cleland JGF Increased alveolar-capillary membrane resistance to gas ransfer in chronic heart failure. Br Heart $\mathcal{f}$ (in press)

61 Cleland JGF, Gillen G, Dargie HJ. The effects of frusemide and angiotensin-converting enzyme inhibitors and their combination on cardiac and renal haemodynamics in heart failure. Eur Heart f 1988;9:132-41.

62 Webster MW, Fitzpatrick MA, Nicholls MG, Ikram $H$ Wells JE. Effects of enalapril on ventricular arrhythmias in heart failure. Am $\mathcal{F}$ Cardiol 1985;56:566.

63 Fletcher RD, Cintron GB, Johnson G, Orndorff J, Carson P, Cohn JN, for the V-HeFT II VA Cooperative Studies Group. Enalapril decreases prevalence of ventricular tachycardia in patients with chronic congestive heart failure. Circulation 1993;87(suppl):VI-49-56.

64 Packer M, Rouleau J-L, Lemuel A, et al. Effect of captopril on ventricular arrhythmias and sudden death in patients with left ventricular dysfunction after myocardial infarction: SAVE trial [abstract]. $\mathcal{F} \mathrm{Am}$ Coll Cardiol 993:21(suppl):130A.

65 Pratt C, Gardner M, Pepine C, et al, for the SOLVD Investigators. Lack of long-term ventricular arrhythmi reduction by enalapril in heart failure patients: doubleblind, parallel, placebo controlled trial. Circulation 1991;84(suppl II): II-348.
66 Cleland JGF. ACE inhibition and heart failure: arrhythmias, catecholamines and electrolytes. Cardiologia 1990;35(suppl 1):441-7.

67 van Gilst WH, de Graeff PA, Wesseling H, de Langen CDJ. Reduction of reperfusion arrhythmias in the ischemic isolated rat heart by angiotensin converting enzyme 498. F Cardiovasc Pharmacol 1986;8:722-8.

68 Bashir Y, Sneddon JF, O'Nunain TA, et al. Comparative electrophysiological effects of captopril or hydralazine combined with nitrate in patients with left ventricular dysfunction and inducible ventricular tachycardia. $\mathrm{Br}$ dysfunction and inducib

69 Captopril Multi-Center Research Group. A placebocontrolled trial of captopril in refractory chronic controlled trial of captopril in refractory chronic 755-63.

70 Newman TJ, Maskin CS, Dennick LG, Meyer JH, Hallows BG, Cooper WH. Effects of captopril on survival in patients with heart failure. $A m \mathcal{F}$ Med 1988;84(suppl $3 \mathrm{~A}): 140-3$.

71 Fonarow GC, Chelimsky-Fallick C, Stevenson LW, et al. Effect of direct vasodilation with hydralazine versus angiotensin converting enzyme inhibition with captopril on mortality in advanced heart failure: the $\mathrm{Hy}-\mathrm{C}$ trial. Am f Cardiol 1992;19:842-50.

72 Yusuf S, Pepine CJ, Garces C, et al. Effect of enalapril on myocardial infarction and unstable angina in patients with low ejection fractions. Lancet 1992;340:1173-8.

73 Davies MJ, Thomas A. Thrombosis and acute coronaryartery lesions in sudden cardiac ischemic death. $N$ Engl 7 Med 1984;310:1137-40.

74 CONSENSUS Trial Study Group. Effects of enalapril on mortality in severe congestive heart failure. Results of the cortality in severe congestive heart failure. Results of the (CONSENSUS). $N$ Engl f Med 1987;316:1429-35.

75 SOLVD Investigators. Effect of enalapril on survival in patients with reduced left ventricular ejection fractions patients with reduced left ventricular ejection fractions and congestive

76 Cleland JGF. Ancillary diagnostic and therapeutic issues in heart failure. Current Opinion in Cardiology 1992;7 408-15

77 Cohn JN, Archibald DG, Ziesche S, et al. Effect of vasodilator therapy on mortality in chronic congestive heart failure. Results of a Veterans Administration cooperative study. N Engl f Med 1986;314:1547-52. 